\title{
Towards Culture-Oriented Medical Philosophy, Education, Research and Practice
}

\author{
Nasser Hammad Al-Azri
}

\section{نحو فلسفة وتعليم وبحث وممارسة طبية ذات ثقافة مجتمعية}

\author{
ناصر بن حماد العزري
}

\begin{abstract}
Medicine is a sociotechnical system wherein culture manifests itself in all its aspects. Culture, however, is often intangible and is frequently neglected in formal healthcare education, research and practice. This sounding board article attempts to generate interest in making culture a serious component of healthcare systems at different levels, including its founding philosophical underpinnings, educational systems, research activities and clinical practice. It is recommended that a framework of culture-oriented medical philosophy, education, research and practice be implemented. Each component of this framework is briefly discussed in relation to healthcare. Culture should be reflected explicitly in healthcare through research activities, medical humanities, cultural competence, communication and ethics.
\end{abstract}

Keywords: Medicine; Medical Education; Medical Philosophy; Biomedical Research; Communication; Bioethics; Culture; Policy Making.

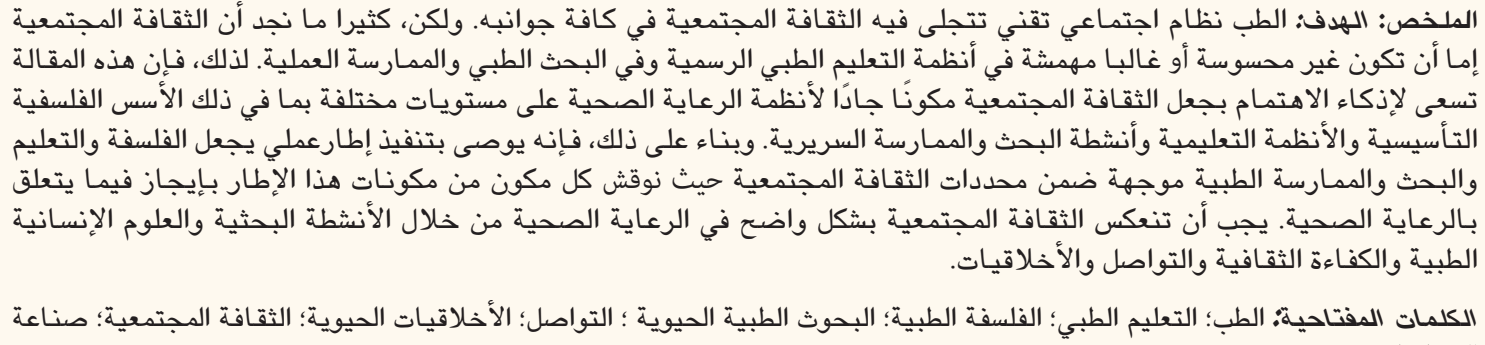

$\mathrm{M}$ EDICINE AND HEALTHCARE FORM A SOCIAL system with complex interactions among the various scientific, social, cultural, religious and philosophical backgrounds that form society's particular worldviews. This paper aims to emphasise the importance of culture in medicine and reiterate the genuine need for reconsidering culture's role in it. In particular, this paper advocates for culture-oriented medical philosophy, education, research and practice (COM-PhERP). Each component-philosophy, education, research and practice-is discussed in terms of its link to culture and medicine. This paper does not aim to present a detailed account of the topic but rather to assert the need for and spark interest in adopting a greater cultural orientation in the medical field.

\section{Culture in Medicine}

Culture is not easily defined. Raymond Williams considered the word "culture" to be "one of the two or three most complicated words in the English language".
Culture involves an amalgamation of factors including personal psychology, perceptions of time and space, proximity to authority and power, dignity and facial recognition, religion, language, uncertainty avoidance, individualism versus collectivism and masculinity versus femininity. Trying to combine these factors into a single definition results in varying perspectives. Culture is often conceptualised as a way of life that is learned, shared and transmitted by members of a particular group or society. ${ }^{2}$

There is probably no social activity or behaviour that does not involve culture in some way. While Shenkar correctly asserts that "culture does not explain everything," it is certainly everywhere and in everything and so must be acknowledged in medicine. ${ }^{3}$ Unfortunately, culture's influence on societal health is often considered distal, diffuse and unspecified; consequently, it is an underestimated determinant of population health, which can have serious implications for medical practice. ${ }^{4}$ 
Considering culture in medicine can be highly advantageous and yield positive results by helping aligning healthcare systems with societal as well as the patient's values. For instance, a national survey on alternative medicine in the United States found that most people who engage in alternative healthcare practices do so because of it is in alignment with their values and beliefs rather than due to a dissatisfaction with biomedicine. ${ }^{5}$ Aligning healthcare systems with patients' values and worldviews may also improve patient compliance when individuals begin to see their healthcare system as conforming to their needs. Consequently, integrating cultural awareness into medicine should lead to safer and more efficient healthcare systems.

In contrast, an ignorance of culture's impact and biases can have serious medical implications. ${ }^{6}$ Miscommunication, noncompliance and discrepancies between patient and practitioner values can limit the benefits of biotechnology and care. Such disconnects can lead to inefficient systems that negatively impact patient safety and limit population health improvements. Adolf Meyer, Professor of Psychiatry at Johns Hopkins University, argues that "When the patient and the physician agree on the nature of the problem, the patient gets better". ${ }^{\text {. Such agreement }}$ requires an understanding of the cultures involved.

\section{Thinking of Culture in Medicine}

There are many ways to think about the elements of culture and their relationship to medicine. Without a doubt, culture drives medicine because "while medicine benefits from a certain amount of scientific input, culture intervenes at every step of the way". Culture might be considered to consist of four dimensions that form the basis for culture-oriented medicine: cultureoriented medical philosophy, culture-oriented medical education, culture-oriented medical research and culture-oriented medical practice.

\section{CULTURE-ORIENTED MEDICAL PHILOSOPHY}

Philosophy lays the foundation of knowledge. It elicits worldviews and makes them explicit. Practice cannot change without understanding its philosophical underpinnings. Education and its practice within any profession is grounded in a particular philosophy. If this philosophy is not explored, there is a risk of importing and applying educational and clinical practices that may not align with societal needs and expectations. Such oversights can create a dichotomy and result in wasted resources.
Medical philosophy is defined as "a field that seeks to explore fundamental issues in theory, research, and practice within the health sciences, particularly metaphysical and epistemological topics"7 Medicine in every society is grounded in a particular worldview. Mead asserts "The concepts of health and disease are part of man's view of the universe and his place within it". In turn, systems can be viewed through a lens that highlights the theoretical as well as practical aspects of everyday life, helping practitioners align their duties with patients' needs. Systems of medical education and practice should be developed with cultural backgrounds in mind and also be able to change and reflect on societal dynamics.

Healthcare practitioners are rarely taught the philosophical background of medical practice. Many might even think such knowledge adds little or no value to medical practice. Thus, healthcare systems frequently "mask the physician's underlying anxiety and relative impotence to deal with the open-ended, frequently insoluble, problems of life, living, and death that are brought to physicians by their expectant patients". This masking and impotence reflect negatively on healthcare as a discipline that must amalgamate its experimental knowledge with patients' existential enquiries.

To bring cultural awareness into medicine, practitioners must consider the ontological, epistemological and axiological dimensions of medicine, healthcare education and practice. Ontological aspects relate to the questions of existence and reality. Ontology probes the nature of being human and the social facts of health and illness. ${ }^{9}$ Considering medicine's epistemological background helps practitioners determine appropriate questions, research methodologies and tools to use and actions to take. Axiology focuses on worth in society which relates to bioethical issues. ${ }^{9}$ Studying these philosophical underpinnings should not be considered a purely theoretical exercise but rather a key to developing culturally guided and bioethically acceptable medical education, research and practice.

Healthcare policy solidifies the concepts of medical and healthcare philosophy. Policy bridges the gap between theoretical philosophical underpinnings and the practical aspects of medical education, research and practice. Practically, culture is an important, yet neglected, component in healthcare policy and planning. ${ }^{10}$ Healthcare policymakers need cultural awareness to understand how health and well-being are perceived within a particular society in order to develop more effective and equitable health policies. ${ }^{11}$ Moreover, public trust in healthcare systems reflects cultural dimensions, which in turn affects public 
orientation towards healthy lifestyles, such as a healthy diet. ${ }^{12,13}$ Medical professionals, therefore, must understand philosophical worldviews and incorporate cultural dimensions in societal healthcare policymaking.

\section{CULTURE-ORIENTED MEDICAL EDUCATION}

Education plays a social role far beyond transference of knowledge and skills from teachers to students. It is the bridge between societal worldviews and a community's daily practices. Medical education transforms cultural values and beliefs about health and illness from theoretical societal worldviews into a platform on which practice can build a strong base. Academic medicine carries implicit and explicit worldviews about life, health, illness and the practice of medicine. These worldviews manifest themselves in educational objectives, curricular priorities, teaching methods and training approaches. ${ }^{14}$ The German Society for Medical Education (Gesellschaft für Medizinische Ausbildung), Committee on Cultural Competence and Global Health's position paper advocates for integrating cultural aspects into existing subject curricula. ${ }^{15}$ Minding the philosophical underpinnings of medical education is essential to developing culturally competent medical practices. Cultural competence has become a requirement of healthcare professionals' education and the need for it cannot be denied. ${ }^{16}$

Unfortunately, a disconnect between culture and medical education is not uncommon. In a study of urban medical environments, Malone et al. found a significant cultural mismatch between physicians and their residents and medical students, ultimately negatively impacting the programme's curriculum design and implementation. ${ }^{17}$ Moreover, certain national cultural characteristics can hinder or enhance medical education and innovation. ${ }^{18}$ Considering medical education's cultural dimensions may guide curricular activities and augment innovation.

\section{CULTURE-ORIENTED MEDICAL RESEARCH}

Science is a social enterprise and research is a tool for exploring social phenomena in society. ${ }^{19}$ Researching cultural aspects of health and illness may boost understanding of these phenomena and help build more efficient and culturally-oriented healthcare systems. Culture also is a determinant of research on societal impact. ${ }^{20}$ The ability to influence culture is the ability to influence conceptions that may affect health behaviour in society. ${ }^{19}$

Technical scientific knowledge may be considered the 'hardware' of societal health behaviour. This 'hardware', however, does not operate in a vacuum; rather, it needs 'software' informed by cultural knowledge. Culture alters the physical environment as much as the physical environment transforms culture. ${ }^{21}$ Hardware and software cannot operate in isolation from each other. If research-and the practice that follows it-focuses only on 'hardware' and ignores the 'software' (or vice versa), it is unlikely to impact society effectively or efficiently.

Unfortunately, although technical knowledge abounds, the cultural knowledge to implement it is lacking. ${ }^{21}$ Greater investment is needed in researching culture and acculturating research in order to enrich and advance the practice of healthcare research. Researching culture includes digging deep to understand relationships between health and illness. By enhancing the 'software' informed by cultural knowledge, practitioners would improve their understanding of societal behaviours around health promotion. Acculturating research prioritises, designs, conducts, interprets and implements changes through empirical findings which are framed within a cultural paradigm.

Developing countries generally are so immersed in the technical knowledge (i.e. the 'hardware') of applied sciences that the social sciences including cultural studies (i.e. the 'software') are mainly considered theoretical exercises. Medical research, however, needs to be envisioned as a socio-technical endeavour. ${ }^{22}$ Although incorporating cultural considerations in health systems research is challenging, encouraging culture-oriented, medically applied research which integrates 'hardware' and 'software' can help achieve a more effective healthcare system. ${ }^{10}$

\section{CULTURE-ORIENTED MEDICAL PRACTICE}

Healthcare professionals do not practice value-free techniques and they do not exercise skills that are divorced of culture. Assumptions and beliefs frame thinking and guide such value-laden practice. Medical practice, however, is just the tip of the values, norms, philosophies and worldviews 'iceberg.' Whether considering scientific knowledge or the art of medical delivery, culture manifests itself in most stages of clinical practice.

The extent to which different countries apply scientific knowledge in clinical medicine varies remarkably. Payer noted "Not only do ways of delivering medical care differ from country to country; so does the medicine that is delivered. The differences are so great that one country's treatment of choice may be considered malpractice across the border". She added "The same clinical signs may even receive 
different diagnoses. Often, all one must do to acquire a disease is to enter a country where that disease is recognised-leaving the country will either cure the malady or turn it into something else".

Cultural values and worldviews are often most strongly embodied in bioethics and communication. Practical bioethics must be culturally grounded due to its relationship to ethical considerations. The dominant approach in modern biomedical practice is principlism, represented by autonomy, beneficence, nonmaleficence and justice-four principles that carry different meanings across cultures and are not universally applicable. ${ }^{23,24}$ Unfortunately, bioethics principlists rarely consider cultural assumptions and variations, resulting in a lack of cultural perspective around the four principles. ${ }^{25}$ When applied to cultures with different understandings of these principles, problems can arise.

Communication, which is central to clinical practice and includes everything that speaks to patients verbally and nonverbally while they are receiving healthcare, is also culturally mediated. Communication includes the language used, a person's tone of voice and body language, the design of the hospital environment and even the signs in the corridors. Understanding cultural dimensions may help contextualise communication processes and give a better sense of doctor/ patient roles in a clinical encounter. ${ }^{26}$ Unfortunately, there is evidence showing that physicians in training are becoming less empathetic and demonstrate declining communication skills as they progress in their medical education. ${ }^{27,28}$ Efforts to improve technical aspects of healthcare services or patient experiences without improving communication are doomed to failure. ${ }^{29}$

\section{Challenges and Limitations}

Culture is like air-it is everywhere-but its presence goes unnoticed until we experience its absence. Its intangibility, however, does not negate its existence. ${ }^{4}$ Considering culture in medicine and incorporating it consciously in medical education, research and practice is important but, unfortunately, it is not straightforward. The process of framing culture in relation to medical practice will likely face many challenges and limitations.

One major challenge is to bring subconscious cultural assumptions to the surface to think about them consciously. It is particularly true that once immersed within a particular cultural worldview, people tend to neglect other worldviews or consider them irrelevant. Payer noted the common ground between French and American medical practices lamenting that "Many of the practices I had taken for granted now seemed to be not so much the result of scientific progress but rather outgrowths of American cultural biases that in some cases harmed more than helped our health and wellbeing".

Another challenge is that culture is commonly considered an ethnic phenomenon. For example, the Western/non-Western dichotomy is often referred to as a core element in two sets of cultures and their related ethos. ${ }^{30}$ However, this dichotomy is artificial and oversimplifies differences. The generalisation could even be considered harmful as "it blinds us to real differences within each region". ${ }^{31}$ There are as many differences within Western communities as there are within non-Western communities; likewise, "many comparisons have shown that while doctors within a given country differ somewhat, doctors from different countries differ even more". ${ }^{6}$ Distinctions in ethos are due less to the Western/non-Western dichotomy and more to cultural backgrounds and biases.

While it might be safe to assume that the closer cultures are in their worldviews, geography and history, the more likely they are to share cultural characteristics, there will still be varying degrees of difference. For example, in examining the differences in Saudi Arabian, Kuwaiti and Omani values, Robertson et al. found that the three countries share a belief system deeply rooted in Islam. Each country's emphasis on the fundamental values they share, however, differs significantly. ${ }^{32}$ This example shows how generalisations in cultural comparisons can be problematic.

The call for COM-PhERP is not a call for a rigid or limited approach to medical education, research and practice. Instead, Ahmad noted, "To be of value, either in exploratory or practical terms, 'culture' needs to be recognised as a context, itself flexible and contested, interacting with, shaping and shaped by other social and structural contexts of people's lives.".3 This call recognises the potential that culture offers for medical education, research and practice in particular, and healthcare as a social system in general.

It is also worth noting that culture is not an 'all or none' phenomenon. Rather, it should be incorporated and analysed consciously and critically. Some cultural processes can be health hazards in and of themselves. ${ }^{4}$ This potential threat to health is a good reason to incorporate culture within medical education, research and practice. Doing so would allow implicit and taken-for-granted concepts to be made explicit and brought to the surface for discussion, analysis and better understanding. 


\section{The Way Forward}

Incorporating culture in healthcare is not a theoretical exercise. Sociological, anthropological and cultural studies can be utilised to build better healthcare systems. Despite its seemingly elusive nature, the concept of culture can be addressed at several levels, and the following practical approach ties research, medical humanities, cultural competence, communication and ethics in this pursuit. Interestingly, the way forward in addressing the concept of culture in medicine is also culturally mediated.

Healthcare practitioners hold varying perspectives on health, illness and life, especially in the current era of strong cultural diversity. Medical education and practice, however, generally lack the perspectives offered by medical humanities. ${ }^{34}$ An understanding of medical humanities is needed as it focuses on interacting with others and understanding the meanings assigned to different situations within the medical context. ${ }^{35}$ Integrating humanities in medical education can help future practitioners develop essential skills of professionalism, communication, self-awareness and reflective practice towards a more holistic approach to their clinical work..$^{36}$

Moreover, the cultural competence movement in healthcare is increasingly recognised at an international level..$^{37}$ One might assume that healthcare students in their native countries practicing among their compatriots would be culturally competent. In fact, their original concepts of health, well-being and illness change during their medical training when interacting with different cultures of education. In this way, their original conceptualisation of health, well-being and illness is modified. ${ }^{38}$ Consequently, it is essential to re-think how to address health and illness issues from a culturally competent perspective, even for locally-educated healthcare professionals. Cultural competence, rather than being limited to selective medical courses, should be inclusive, permeating medical education, research and practice. Cultural competence in clinical practice can provide a more holistic approach to patient care.

Culture manifests itself vividly in communication and ethics-two essential components of medicine. It is surprising, therefore, that a subject so deeply grounded in culture is mostly absent when students are medically trained in a foreign language in medical and allied health schools. Medical educators must teach from a cultural perspective, allowing future healthcare providers to apply these perspectives in practice. Based on the authors' experience in teaching bioethics to medical residents and communication to nursing students, the participants' experiences and comprehension were greatly enhanced when their mother tongue (i.e. Arabic) was used with culturally illustrative approaches. Once these suggested approaches start to permeate medical education, research and practice, culture will become an integrative part of medical practice.

Miller suggested that "Medicine spans the two ends of the [art-science] spectrum: one foot is planted in the physical world, electronic impulses and the muck of the human body; the other is planted in the subjective experiential world of consciousness and conduct". ${ }^{39}$ Culture offers a chance to appreciate and utilise the subjective world of medicine. Therefore, in the bigger picture of health and healthcare in societies, a culture-oriented medical philosophy as well as education, research and practice imbued in culture are needed.

\section{Conclusion}

Culture is a critical ethereal component of medicine and healthcare. This paper presented a glimpse into COM-PhERP. These components share individual elements while also presenting an opportunity for cohesive integration. In order to acknowledge culture and its importance, this paper suggests utilising research, medical humanities, cultural competence, communication and ethics to crystallise the concept of culture within medicine and healthcare. If culture is not incorporated and utilised purposefully and consciously, healthcare providers may lose opportunities for enhancing health and bettering healthcare for society. Policymakers, educators, researchers and practitioners in healthcare need to address culture as an integrative, core component of all healthcare activities.

\section{References}

1. Williams R. Keywords: A vocabulary of culture and society. New York, USA: Oxford University Press, 2014. P. 87.

2. Haralambos M, Holborn M. Sociology: Themes and perspectives. 7th ed. London, UK: HarperCollins UK, 2008. P. 663

3. Shenkar O, Luo Y. International business. 2nd ed. Los Angeles, USA: Sage Publications, 2008.

4. Eckersley R. Is modern Western culture a health hazard? Int J Epidemiol 2006; 35:252-8. https://doi.org/10.1093/ije/dyi235.

5. Astin JA. Why patients use alternative medicine: Results of a national study. JAMA 1998; 279:1548-53. https://doi.org/10.10 01/jama.279.19.1548

6. Payer L. Medicine and culture. New York, USA: Henry Holt and Company, 1996.

7. Reiss J, Ankeny RA. Philosophy of medicine. From: https:// plato.stanford.edu/archives/sum2016/entries/medicine/ Accessed: Jun 2020 
8. Mead M. Cultural patterns and technical changes. New York, USA: The New American Library, 1955. P. 245.

9. Edelheim JR. Ontological, epistemological and axiological issues. In: Dredge D, Airey D, Gross MJ (eds), The Routledge Handbook of Tourism and Hospitality Education. London: Routledge, 2015. P. 30-42.

10. Atkinson S. Political cultures, health systems and health policy. Soc Sci Med 2002; 55:113-24. https://doi.org/10.1016/S02779536(01)00213-1.

11. Napier DA, Depladge M, Knipper M, Lovell R, Ponarin E, Sanabria E, et al. Culture matters: using a cultural contexts of health approach to enhance policy-making. From: www.euro. who.int/ data/assets/pdf file/0009/334269/14780 WorldHealth-Organisation_Context-of-Health_TEXT-AW-WEB.pdf Accessed: Jun 2020.

12. van der Schee E, Braun B, Calnan M, Schnee M, Groenewegen PP. Public trust in health care: A comparison of Germany, the Netherlands, and England and Wales. Health Policy 2007; 81:56-67. https://doi.org/10.1016/j.healthpol.2006.04.004.

13. Sun T, Horn M, Merritt D. Impacts of cultural dimensions on healthy diet through public self-consciousness. J Consum Mark 2009; 26:241-50. https://doi.org/10.1108/07363760910965846.

14. Tilburt J, Geller G. The importance of worldviews for medical education. Acad Med 2007; 82:819-22. https://doi.org/10.1097/ ACM.0b013e3180d098cc.

15. Mews C, Schuster S, Vajda C, Lindtner-Rudolph H, Schmidt LE, Bösner S, et al. Cultural competence and global health: Perspectives for medical education - Position paper of the GMA Committee on Cultural Competence and Global Health. GMS J Med Educ 2018; 35:Doc28. https://doi.org/10.3205/zma001174.

16. Shaya FT, Gbarayor CM. The case for cultural competence in health professions education. Am J Pharm Educ 2006; 70:124 https://doi.org/10.5688/aj7006124.

17. Malone B, Hasan S, Sanni A, Reilly J. Mismatch of cultural dimensions in an urban medical educational environment. J Biomed Educ 2013; 617674. https://doi.org/10.1155/2013/617674.

18. Jippes M, Majoor GD. Influence of national culture on the adoption of integrated medical curricula. Adv Health Sci Educ Theory Pract 2011; 16:5-16. https://doi.org/10.1007/s10459010-9236-5.

19. Kuruvilla S, Mays N, Pleasant A, Walt G. Describing the impact of health research: A research impact framework. BMC Health Serv Res 2006; 6:134. https://doi.org/10.1186/1472-6963-6-134.

20. Leroy JL, Habicht JP, Pelto G, Bertozzi SM. Current priorities in health research funding and lack of impact on the number of child deaths per year. Am J Public Health 2007; 97:219-23. https://doi.org/10.2105/AJPH.2005.083287.

21. Graham SA. The sociological approach to epidemiology. Am J Public Health 1974; 64:1046-9. https://doi.org/10.2105/ajph.6 4.11.1046

22. Al-Azri NH. Do we need a new medical paradigm? Oman Med J 2012; 27:256-7. https://doi.org/10.5001/omj.2012.60.

23. Beauchamp TL, Childress JF. Principles of Biomedical Ethics. 7th ed. New York: Oxford University Press, 2001.
24. Ali M. The "bio" in biomedicine: Evolution, assumptions, and ethical implications. In: Ghaly M, Ed. Islamic Perspectives on the Principles of Biomedical Ethics. London, UK: World Scientific Publishing, 2016. P. 41-67

25. Traphagan JW. Rethinking autonomy: A critique of principlism in biomedical ethics. New York, USA: State University of New York Press, 2013. P. 31

26. Verma A, Griffin A, Dacre J, Elder A. Exploring cultural and linguistic influences on clinical communication skills: A qualitative study of international medical graduates. BMC Med Educ 2016; 16:162. https://doi.org/10.1186/s12909-016-0680-7.

27. Woloschuk W, Harasym PH, Temple W. Attitude change during medical school: A cohort study. Med Educ 2004; 38:522-34. https://doi.org/10.1046/j.1365-2929.2004.01820.x.

28. Hojat M, Vergare MJ, Maxwell K, Brainard G, Herrine SK, Isenberg GA, et al. The devil is in the third year: A longitudinal study of erosion of empathy in medical school. Acad Med 2009; 84:1182-91. https://doi.org/10.1097/ACM.0b013e3181b17e55.

29. Cosgrove T. The Cleveland Clinic way: Lessons in excellence from one of the world's leading health care organizations. New York, USA: McGraw-Hill Education, 2014

30. Al-Saadoon M, Al-Adawi S. Informed consent in societies with different ethos of 'selfhood'. Sultan Qaboos Univ Med J 2019; 19:e1-3. https://doi.org/10.18295/squmj.2019.19.01.001.

31. Mead R, Andrews TG. International Management, 4th ed. West Sussex, UK: Wiley-Blackwell, 2009. P.9.

32. Robertson CJ, Al-Khatib JA, Al-Habib M, Lanoue D. Beliefs about work in the Middle East and the convergence versus divergence of values. J World Bus 2001; 36: 223-44. https://doi. org/10.1016/S1090-9516(01)00053-0.

33. Ahmad WIU. The trouble with culture. In: Kelleher D, Hillier S, Eds. Researching Cultural Differences in Health. London, UK: Routledge, 1996. P. 190-219.

34. Al-Azri NH. Sent to explore, conquer and heal: History of the evolution of biomedicine in Oman during the 19 century. Sultan Qaboos Univ Med J 2011; 11:187-95.

35. Malpas P, Jowsey T. Humanities for medical students: Essential to their cultural competence and patient-engaged practices of care. Med Ed Publish 2018. https://doi.org/10.15694/mep.20 18.0000202.1.

36. Wald HS, McFarland J, Markovina I. Medical humanities in medical education and practice. Med Teach 2019; 41:492-6. https://doi.org/10.1080/0142159X.2018.1497151.

37. Betancourt JR, Green AR, Carrillo JE, Ananah-Firempong O 2nd. Defining cultural competence: A practical framework for addressing racial/ethnic disparities in health and health care. Public Health Rep 2003; 118:293-302. https://doi.org/10.1093/ $\mathrm{phr} / 118.4 .293$

38. McGarvey A, Brugha R, Conroy RM, Clarke E, Byrne E. International students' experience of a western medical school: A mixed methods study exploring the early years in the context of cultural and social adjustment compared to students from the host country. BMC Med Educ 2015; 15:111. https://doi. org/10.1186/s12909-015-0394-2.

39. McManus IC. Humanity and the medical humanities. Lancet 1995; 346:1143-5. https://doi.org/10.1016/s0140-6736(95)91806-x. 